\title{
ANALISIS PEMASARAN LAYANAN INFORMASI DEPOK CORNER (PEMASARAN LAYANAN INFORMASI REFERENSI DI PERPUSTAKAAN UMUM KOTA DEPOK)
}

\section{Ceria Isra Ningtyas*}

\begin{abstract}
Abstrak
Depok Corner merupakan salah satu bentuk inovasi dari Perpustakaan Umum Kota Depok yang menyediakan berbagai informasi mengenai Kota Depok yang bertujuan untuk mempermudah masyarakat dalam memperoleh informasi mengenai Kota Depok. Layanan Depok Corner telah menerapkan 7 elemen pemasaran yaitu product, price, promotion, place, people, process and physical evidence. Depok Corner diharapkan sebagai solusi mempermudah warga dalam mengakses informasi tentang kota Depok seluruhnya.
\end{abstract}

Kata kunci: pemasaran, marketing mix, perpustakaan.

\section{PENDAHULUAN}

Undang-Undang Nomor 43 Tahun 2007 tentang Perpustakaan Pasal 1 ayat (1) menjelaskan bahwa perpustakaan merupakan institusi pengelola rekaman gagasan, pemikiran, pengalaman dan pengetahuan umat manusia serta mempunyai fungsi utama melestarikan hasil budaya umat manusia khususnya yang berbentuk dokumen karya tulis, karya cetak dan/atau karya rekam lainnya, dengan tujuan memberikan layanan kepada pemustaka, meningkatkan kegemaran membaca dan wahana belajar sepanjang hayat. Pada Pasal 1 ayat (6) disebutkan bahwa perpustakaan umum adalah perpustakaan yang diperuntukkan bagi masyarakat luas sebagai sarana pembelajaran sepanjang hayat tanpa membedakan umur, jenis kelamin, suku, ras, agama, dan status sosial-ekonomi. Layanan perpustakaan dilakukan secara prima dan berorientasi bagi kepentingan pemustaka sebagaimana tersebut dalam Pasal 14 ayat (1).

Perpustakaan umum di Indonesia yang masuk dalam project International Networking of Emerging Library Innovators (INELI) untuk negara-negara ASEAN adalah Perpustakaan Umum Kota Depok. Hasil project tersebut menyebutkan bahwa keberadaan Perpustakaan Umum Kota Depok dinilai sebagai perpustakaan dengan memiliki dampak terbaik bagi warga di tingkat ASEAN. Perpustakaan Umum Kota Depok yang mewakili Indonesia dinilai oleh peserta ASEAN paling baik kedua. Perpustakaan Umum Kota Depok berhasil menyisihkan perpustakaan umum tingkat kota seperti di negara seperti Myanmar, Kamboja, Laos, hingga Timor Leste.

Jika dilihat dari struktur organisasinya sejarah pendiriannya, Perpustakaan Umum Kota Depok adalah bagian dari Dinas Kearsipan dan Perpustakaan Kota Depok merupakan Organisasi Perangkat Daerah (OPD) yang menjalankan urusan pemerintahan non layanan dasar bidang perpustakaan sesuai dengan Peraturan Walikota Depok Nomor 79 Tahun 2016 tentang Susunan Organisasi, Tugas dan Fungsi Tata Kerja Dinas Kearsipan dan Perpustakaan Kota Depok.

Perpustakaan Umum Kota Depok menempati gedung baru yang telah diresmikan pada 27 April 2015 lalu oleh Walikota Depok Nur Mahmudi Ismail, atau bertepatan dengan HUT ke-16 Kota Depok. Pembangunan gedung baru ini adalah upaya dalam memudahkan masyarakat dalam mencari referensi informasi di Kota Depok. Gedung perpustakaan yang berada tepat di depan lapangan Balai Kota Depok terdiri dari tiga lantai. Pada penempatannya, buku-buku diletakkan pada lantai 2 dan

\footnotetext{
* Pustakawan Biro Hubungan Masyarakat dan Informasi Publik, Sekretariat Jenderal Kementerian Pertanian

E-mail: ceria.israningtyas@ pertanian.go.id
} 
lantai 3. Lantai dua terdiri dari buku-buku umum dan pengunjung dapat meminjam. Sementara itu, di lantai tiga terdapat buku-buku referensi dimana pengunjung hanya dapat membacanya pada tempat yang disediakan. Gedung ini dilengkapi dengan arena bermain anak, ruang teater, ruang Depok Corner, dan auditorium yang sering disebut sebagai "Smart Space Room". Layanan yang diberikan kepada pengguna berupa layanan informasi perpustakaan, sirkulasi koleksi dan terbitan berkala, internet, perpustakaan keliling, koleksi anak, kunjungan edukasi, serta Depok Corner. Adapun fasilitas lainnya yaitu Online Public Access Catalog (OPAC), WIFI, serta layanan keanggotaan berbasis web.

Depok Corner dipandang sebagai layanan dari Perpustakaan Umum Kota Depok yang berbeda dengan perpustakaan umum di kota lainnya di Indonesia. Depok Corner merupakan salah satu bentuk inovasi dari Perpustakaan Umum Kota Depok yang menyediakan berbagai informasi mengenai Kota Depok yang bertujuan untuk mempermudah masyarakat dalam memperoleh informasi mengenai Kota Depok.

Dalam mengeksplorasi mengenai pemasaran layanan informasi referensi pada perpustakaan umum, penulis tertarik untuk membahas bagaimana analisis pemasaran layanan informasi Depok Corner di Perpustakaan Umum Kota Depok. Secara teoretis, makalah ini diharapkan dapat memberikan penjelasan analisa pemasaran layanan informasi referensi pada perpustakaan umum. Secara praktis, makalah ini diharapkan dapat memberikan masukan bagi pimpinan dan pengelola perpustakaan, terutama perpustakaan umum dalam menganalisa produk layanan informasi referensinya agar tepat sasaran.

\section{TINJAUAN PUSTAKA}

\section{Strategi Pemasaran}

Pendekatan strategi pemasaran (marketing) menurut Kavulya (2004) dalam Garoufallou, Emmanouel, et.al, 2013 menyatakan bahwa:

"[...] is a management process that involves planning, requires analysis of customer needs and ways satisfying those needs, and is geared towards mutual benefit for customers as well as the organization".

Adapun 4 (empat) tahapan dasar dalam perencanaan pemasaran menurut buku Strategic Marketing tentang The "Marketing@your library" (dalam Garoufallou, Emmanouel, et.al, 2013) menyebutkan: (1) Customer and market research (customer needs and customer view); (2) Strategic library plan (vision and mission, products and services implementation); (3) Promotion of the library (messages, vehicles, campaign implementation and;

(4) Providing products/services (delivery interaction adjustments).

Konsep marketing mix terus berkembang menjadi 7P yaitu product, price, promotion, place, people, process and physical evidence. (Arief, 2006 dalam Fahriyah: 2015). Produk adalah segala sesuatu yang ditawarkan oleh perusahaan kepada konsumen untuk memenuhi kebutuhannya. Harga adalah strategi penentuan harga/ biaya yang harus dikeluarkan oleh konsumen untuk mendapatkan sesuatu. Promosi sebagai cara untuk mengkomunikasikan manfaat jasa kepada konsumen. Tempat adalah lokasi dan saluran distribusi untuk mempermudah konsumen mendapatkan produk yang ditawarkan. Orang yaitu karyawan perusahaan yang bisa memberikan barang dan jasa yang ditawarkan oleh perusahaan. Proses yaitu terjadinya interaksi langsung antara produsen yang melakukan proses produksi dengan konsumen yang memanfaatkan jasa. Sedangkan physical evidence yaitu bukti fisik yang dapat dihubungkan dengan jasa yang ditawarkan.

\section{Strategi Pemasaran Layanan Perpustakaan}

Ketujuh konsep elemen dalam marketing mix tersebut dapat diaplikasikan dalam perpustakaan sesuai dengan hasil penelitian dari Garoufallou, Emmanouel, et al., 2013, dapat dilihat dalam tabel 1.

\section{Analisis Segmentasi Layanan Perpustakaan}

Setelah menyusun strategi pemasaran memakai model marketing mix, langkah selanjutnya adalah analisis segmentasi pasar, dalam hal ini segmentasi layanan perpustakaan. Berdasarkan Sutisna (2002: 248), segmentasi pasar merupakan strategi yang sangat penting dalam mengembangkan program pemasaran, diharapkan usaha-usaha pemasaran yang dilakukan dapat mencapai tujuan perusahaan secara efektif dan efisien. Perpustakaan perlu memastikan kembali segmentasi layanan perpustakaannya. Hal ini diperlukan agar perpustakaan mengetahui siapa sebenarnya yang berkepentingan menikmati layanan perpustakaan yang disediakannya.

Pada Potter (2012: 28-29) disebutkan bahwa segmentasi layanan perpustakaan diawali dengan mengelompokkan kelompok target pengguna menjadi dua kelompok, yaitu kelompok pengguna dan kelompok non-pengguna. Setelah itu, kemudian membagi masing- 
masing kelompok tersebut menjadi segmen yang lebih kecil.

a. Segmentasi Kelompok Pengguna

Data Kelompok Pengguna didapatkan dari database anggota perpustakaan, kemudian dikategorikan berdasarkan usia, jenis kelamin, juga tempat tinggal, dan sebagainya. Selain itu, perlu didata pengguna berdasarkan perilaku dan motivasi mereka dalam menggunakan layanan di perpustakaan. Sehingga didapatkan data detail mengenai anggota perpustakaan yang telah bergabung dan dapat disusun strategi selanjutnya berdasarkan tujuan pemasaran yang ditetapkan oleh perpustakaan misalnya, tujuan pemasaran yang dilakukan adalah mendapatkan pengguna yang sudah ada untuk menggunakan sumber daya layanan informasi secara maksimal.

Table 1. 7P the Elements of Marketing Mix

\begin{tabular}{|c|c|c|}
\hline No. & $\begin{array}{l}\text { 7P the Elements of Marketing } \\
\text { Mix }\end{array}$ & Adjusted to a Library Environment \\
\hline 1. & Product & $\begin{array}{l}\text { The services, the resources and programs offered; e.g. (a) reference services; } \\
\text { (b) loans; (c) opening hours; (d) websites; (e) books; (f) journal collections; (g) } \\
\text { e-resources; (h) databases; (i) printers; (j) training; (k) seminars. }\end{array}$ \\
\hline 2. & Price & $\begin{array}{l}\text { The tangible or intangible price or cost paid to use the library services, } \\
\text { resources and programmes; e.g. (a) Tangible: taxes, fees (b) Intangible: indirect } \\
\text { costs, time spent to find specific information, the kind of experience when } \\
\text { using the library. Library could adopt a pricing policy for different types of } \\
\text { services. }\end{array}$ \\
\hline 3. & Place & $\begin{array}{l}\text { Where and how are the services made available and the users are served; e.g. } \\
\text { (a) At a library departement (b) By telephone (c) Online from the library's } \\
\text { website or (d) Online from a digital library. }\end{array}$ \\
\hline 4. & Promotion & $\begin{array}{l}\text { The way in which a library advertises its services and the methods-tools used } \\
\text { to inform the public. Promotion include: (a) Public relations; (b) Advertising; } \\
\text { (c) Publicity; (d) Personal communications. } \\
\text { Additional tools can be used such as: (a) Brochures; (b) Leaflets; (c) Posters; (d) } \\
\text { Newsletters; (e) User orientation seminars; (f) Book presentations/exhibitions; } \\
\text { (g) Announcements on press and local media. }\end{array}$ \\
\hline 5. & People & $\begin{array}{l}\text { The library staff (reference departement). The way in which they: (a) } \\
\text { Communicate (b) Behave and serve users plays a decisive role (c) Affects } \\
\text { the services quality (d) Create positive and negative perceptions towards the } \\
\text { library. } \\
\text { Specific attributes of staff behaviour include: (a) Educational qualifications (b) } \\
\text { Proffesional experience (c) Appearance (d) Polite behaviour (e) Willingness } \\
\text { to assist (f) Communication skills (g) Quickness in service delivery (h) } \\
\text { Efficiency. }\end{array}$ \\
\hline 6. & Physical evidence & $\begin{array}{l}\text { The impressions created by the surrounding environment in which services } \\
\text { are provided, depend on the specific facilities or virtual library environment } \\
\text { attributes; e.g. (a) Clean and tidy facilities; (b) Buildings architecture; (c) } \\
\text { Decoration; (d) Lighting; (e) Air-conditioning; (f) Quiet; (g) Technological } \\
\text { equipment/accessibility; (h) Usability; (i) Operation; (j) Easy search and } \\
\text { navigation performance. }\end{array}$ \\
\hline 7. & Processes & $\begin{array}{l}\text { The efficiency and effectiveness of human resources management and library } \\
\text { operation to satisfy user needs; e.g. (a) Automation of loans and reference } \\
\text { services (b) Telephone assistance (c) Online information services provision } \\
\text { (Ask a Librarian) }\end{array}$ \\
\hline
\end{tabular}

Sumber: Hasil Penelitian dari Garoufallou, Emmanouel, et al. (2013) 
b. Segmentasi Kelompok Non-Pengguna

Jika salah satu tujuan pemasaran adalah untuk meningkatkan jumlah pengguna perpustakaan, maka perlu dilakukan segmentasi kelompok nonpengguna ke dalam kategori target yang berbeda. Segmentasi jenis ini harus diawali dengan penetapan tujuan yang lebih detail, misalnya pemasaran layanan tertentu untuk mendapatkan 500 orang anggota baru yang terdiri dari 200 anggota dari kalangan kaum muda, 200 anggota dari kalangan keluarga muda, 50 orang pengguna jarak jauh dan 50 pengguna yang sudah berkunjung ke perpustakaan tetapi hanya memanfaatkan WiFi gratis.

Penetapan target yang detail tersebut menjadikan proses pemasaran lebih fokus dan spesifik. Selanjutnya, pengelola perpustakaan dapat melakukan penawaran yang dirancang untuk menarik setiap segmen, memasarkan kepada mereka dan mencatat angka dan mengevaluasi pasca dilakukannya pemasaran.

\section{METODE PENELITIAN}

Metode penelitian menggunakan kualitatif dengan cara observasi langsung di Perpustakaan Umum Kota Depok beralamat di Jalan Margonda Raya Nomor 54, Depok, Jawa Barat. Teknik pengumpulan data diperoleh dari observasi dan studi kepustakaan. Untuk analisa data, dari hasil observasi diolah dan dianalisis berdasarkan hasil penelitian Garoufallou, Emmanouel, et al. (2013).

\section{PEMBAHASAN}

Depok adalah sebuah kota di Jawa Barat yang beberapa tahun terakhir terus berkembang sebagai salah satu kota penyangga ibu kota negara, Jakarta. Wajar bila banyak orang yang ingin berkunjung dan mendapatkan informasi seputar Depok. Sementara itu, informasi atau literatur tentang Depok masih sangat minim, karena masih banyak yang tersebar di berbagai OPD se-Kota Depok, bahkan tak sedikit ada di berbagai komunitas, sehingga sulit menyatukan dalam satu informasi. Berangkat dari latar belakang itu, 4 bulan setelah bertempat di gedung baru Dinas Kearsipan dan Perpustakaan Kota Depok kemudian meluncurkan layanan informasi referensi Depok Corner pada tanggal 28 Agustus 2015 oleh Sekretaris Daerah Kota Depok Harry Prihanto. Depok Corner diharapkan sebagai solusi mempermudah warga dalam mengakses informasi tentang kota Depok seluruhnya.
Berdasarkan analisis data observasi di Perpustakaan Umum Kota Depok terutama untuk layanan informasi referensi Depok Corner, ditemukan beberapa elemen dalam 'Marketing Mix' atau strategi pemasaran perpustakaan yang telah diaplikasikan dalam perpustakaan, dapat dilihat dalam tabel 2 .

Adapun analisis segmentasi pasar yang dilakukan untuk layanan Depok Corner adalah sebagai berikut:

a. Segmentasi Kelompok Pengguna

Kelompok Pengguna Depok Corner adalah anggota perpustakaan yang telah menggunakan layanan ini. Pengguna Depok Corner saat ini berasal dari kalangan pelajar, mahasiswa, juga pegawai Pemerintah Kota Depok.

b. Segmentasi Kelompok Non-Pengguna

Kelompok non pengguna yang diharapkan menggunakan layanan Depok Corner adalah pemangku kebijakan, pengusaha, peneliti multi-disiplin, komunitas yang berada di Kota Depok.

\section{Videografis Depok Corner}

Setelah melakukan analisa $7 P$ the Elements of Marketing Mix dan analisa segmentasi pasar, maka dilakukan rancangan produk videografis terkait layanan informasi pada Depok Corner sebagai alat promosi pada media digital. Hal ini dilakukan karena berdasarkan tujuan dilayankan Depok Corner adalah sebagai solusi mempermudah warga dalam mengakses informasi tentang kota Depok seluruhnya, namun warga belum memaksimalkan layanan ini. Selain itu, penggunaan videografis dianggap memudahkan sebagian orang untuk mempelajari sesuatu karena merupakan gabungan materi audiovisual serta grafis dan teks penjelasannya. Digunakannya videografis sebagai alat promosi dimaksudkan agar informasi yang disampaikan lebih jelas dan menarik sehingga dapat menggugah rasa ingin tahu audiens untuk berkunjung dan akhirnya memanfaatkan layanan informasi yang dilayankan.

Videografis yang dirancang berjudul Layanan Informasi Referensi "Depok Corner" Perpustakaan Umum Kota Depok berdurasi hanya sekitar 2 menit, berisi konten mengenai sekilas gambaran visual Kota Depok, Balaikota Depok, Perpustakaan Umum Kota Depok, dan selebihnya adalah mengenai Depok Corner.

Audiens videografis Depok Corner terdiri dari pelajar, mahasiswa, juga pegawai Pemerintah Kota 
Tabel 2. Penerapan pada Depok Corner

\begin{tabular}{|c|c|c|}
\hline No. & $\begin{array}{l}\text { 7P the Elements of } \\
\text { Marketing Mix }\end{array}$ & Penerapannya pada Depok Corner \\
\hline 1. & Product & $\begin{array}{l}\text { Koleksi yang tersedia di Depok Corner merupakan kerjasama antara Perpustakaan } \\
\text { Umum Kota Depok dengan Dinas atau Badan yang berada di lingkungan } \\
\text { Pemerintah Kota Depok. Komponen layanan yang diberikan meliputi penyediaan } \\
\text { koleksi bentuk fisik berupa terbitan Organisasi Perangkat Daerah (OPD) lingkup } \\
\text { Kota Depok, bahan pustaka, kliping yang memuat informasi tentang Kota Depok } \\
\text { dan penelusuran informasi secara elektronik berupa situs web yang dapat diakses } \\
\text { pada http://kap.depok.go.id/depokcorner/ dan media penelusuran berupa } 1 \text { unit } \\
\text { komputer. }\end{array}$ \\
\hline 2. & Price & $\begin{array}{l}\text { Layanan Depok Corner yang dilakukan untuk penggunanya tidak berbiaya atau } \\
\text { gratis. }\end{array}$ \\
\hline 3. & Place & $\begin{array}{l}\text { Depok Corner dilayankan offline di lantai } 3 \text { Gedung Perpustakaan Umum Kota } \\
\text { Depok sesuai jam buka perpustakaan yaitu Senin s.d. Kamis dan Minggu 08.00- } \\
\text { 15.00, Jumat 08.00-16.00, serta Sabtu 08.00-19.30. } \\
\text { Layanan melalui telepon 021-77200936 dan layanan secara online melalui e-mail } \\
\text { depokcorner@gmail.com }\end{array}$ \\
\hline 4. & Promotion & $\begin{array}{l}\text { Promosi offline yang telah dilakukan untuk Depok Corner melalui standing banner } \\
\text { yang diletakkan pada lobby perpustakaan serta ruang koleksi serta penjelasan } \\
\text { mengenai Depok Corner pada leaflet tercetak. }\end{array}$ \\
\hline & & $\begin{array}{l}\text { Promosi online berupa } \\
\text { pemberitaan pada beberapa media online yaitu: } \\
\text { https://www.depok.go.id/31/08/2015/04-pendidikan-kota-depok/depok-corner- } \\
\text { sarana-meningkatkan-informasi-kota-depok } \\
\text { http://www.republika.co.id/berita/koran/urbana/15/09/02/nu1i3b42-akses- } \\
\text { informasi-kota-di-depok-corner } \\
\text { https://bisnisjakarta.co.id/2018/01/05/perpus-umum-depok-diklaim-terbaik-di- } \\
\text { asean/ } \\
\text { http://m.infonitas.com/features/menariknya-wisata-ke-perpustakaan-umum-kota- } \\
\text { depok/85 } \\
\text { media sosial, yaitu } \\
\text { Facebook: Fanpage Perpustakaan Umum Kota Depok } \\
\text { Twitter: @ Arpus_Depok } \\
\text { Instagram: perpustakaanumumdepok } \\
\text { Youtube: Depok Corner }\end{array}$ \\
\hline 5. & People & $\begin{array}{l}\text { Petugas layanan informasi referensi pada Depok Corner yang merupakan Kepala } \\
\text { Seksi Perpustakaan dan Pustakawan yang berasal dari latar belakang pendidikan } \\
\text { S1 Ilmu Perpustakaan telah menunjukkan kemampuan melayani informasi secara } \\
\text { komunikatif dan informatif. }\end{array}$ \\
\hline 6. & Physical evidence & $\begin{array}{l}\text { Ruangan layanan Depok Corner dinilai telah baik, bersih, rapih, walaupun dekorasi } \\
\text { yang ditampilkan masih monoton. Koleksi yang terdapat pada Depok Corner } \\
\text { disajikan pada beberapa rak buku hanya dapat dibaca di tempat (tidak dipinjamkan } \\
\text { dan atau/dibawa pulang). }\end{array}$ \\
\hline 7. & Processes & $\begin{array}{l}\text { Layanan Depok Corner berupa baca koleksi tercetak di tempat, layanan informasi } \\
\text { digital pada situs web http://kap.depok.go.id/depokcorner/, serta layanan konsultasi } \\
\text { terkait informasi Kota Depok melalui saluran komunikasi telepon, e-mail, dan } \\
\text { media sosial. }\end{array}$ \\
\hline
\end{tabular}


Depok, pemangku kebijakan, pengusaha, peneliti multidisiplin, komunitas yang berada di Kota Depok.

Videografis ini akan didiseminasikan pada media sosial Pemerintah Kota Depok dan Perpustakaan Umum Kota Depok, media centre layanan publik lingkup Pemerintah Kota Depok (kantor Dinas dan Kecamatan/Kelurahan), media centre layanan publik lingkup Kota Depok seperti kantor polisi, kantor bank, juga perguruan tinggi negeri maupun perguruan tinggi swasta yang terdapat di Kota Depok. Untuk diseminasi di Perpustakaan Umum Kota Depok dilakukan pada digital gallery di lobby serta penayangan di setiap event yang bertema tentang Kota Depok yang dilaksanakan di perpustakaan.

Penayangan videografis Depok Corner dapat dilakukan selama 1 (satu) bulan pada tempat-tempat yang telah disebutkan di atas, kemudian dapat dilakukan evaluasi berdasarkan feedback juga respons dari masyarakat audiens.

\section{KESIMPULAN}

Layanan Depok Corner telah menerapkan 7 elemen pemasaran tersebut dalam melayani pengguna perpustakaan yaitu produk dan layanan yang berorientasi pada kebutuhan dan keinginan pengguna. Kemudian berbagai bentuk atau variasi layanan yang telah dilaksanakan, pustakawan dan petugas perpustakaan juga berusaha terus menerus memahami keinginan penggunanya, kejelasan kapan dan dimana pengguna dapat menemukan dan menggunakan informasi yang tersedia di ruangan Depok Corner maupun melalui situs web.
Depok Corner sebagai layanan informasi referensi disajikan pada berbagai saluran komunikasi. Pejabat Perpustakaan dan Pustakawan berasal dari pendidikan formal S1 Ilmu Perpustakaan telah memiliki kemampuan berkomunikasi dan kemampuan dalam melayani informasi telepon, e-mail, dan media sosial, serta situs web http://kap.depok.go.id/depokcorner/. Dalam penerapan konsep marketing, perpustakaan diperbolehkan menarik biaya yang disesuaikan dengan tipe layanan dalam perpustakaan, walaupun perpustakaan termasuk organisasi non profit, akan tetapi di Perpustakaan Umum Kota Depok tidak menarik biaya atau gratis dalam memberikan semua layanannya, termasuk layanan Depok Corner.

Videografis terkait layanan informasi pada Depok Corner sebagai alat promosi pada media digital perlu dirancang agar layanan informasi referensi ini dapat diketahui dan dimanfaatkan oleh berbagai kalangan di Kota Depok.

\section{DAFTAR PUSTAKA}

Fahriyah. 2015. Strategi Pemasaran di Arsip dan Perpustakaan Kota Surabaya. Record and Library Journal Volume 1, Nomor 2, Juli-Desember 2015 (198208).

Garoufallou, Emmanouel, et.al. 2001. The Use of Marketing Concepts in Library Services : a Literature Review. Library Review, 62(4/5),312-334. Diunduh dari www. emeraldinsight.com/0024-2535.htm. pada 8 April 2018.

Potter, Ned. 2001. The library marketing toolkit. Facet Publishing.

Sutisna. 2002. Perilaku Konsumen dan Komunikasi Pemasaran. Bandung : Remaja Rosdakarya. 